Portland State University

PDXScholar

\title{
A contextualized grammar proficiency test using informal spoken English
}

Sally Wellenbrock Hinrich

Portland State University

Follow this and additional works at: https://pdxscholar.library.pdx.edu/open_access_etds

Part of the English Language and Literature Commons, and the Linguistics Commons Let us know how access to this document benefits you.

\section{Recommended Citation}

Hinrich, Sally Wellenbrock, "A contextualized grammar proficiency test using informal spoken English" (1988). Dissertations and Theses. Paper 3816.

https://doi.org/10.15760/etd.5700

This Thesis is brought to you for free and open access. It has been accepted for inclusion in Dissertations and Theses by an authorized administrator of PDXScholar. Please contact us if we can make this document more accessible: pdxscholar@pdx.edu. 
AN ABSTRACT OF THE THESIS OF Sally Wellenbrock Hinrich for the Master of Arts in English:TESOL presented June 2, 1988 .

Title: A Contextualized Grammar Proficiency Test Using Informal Spoken English.

APPROVED BY MEMBERS OF THE THESIS COMMITTEE:

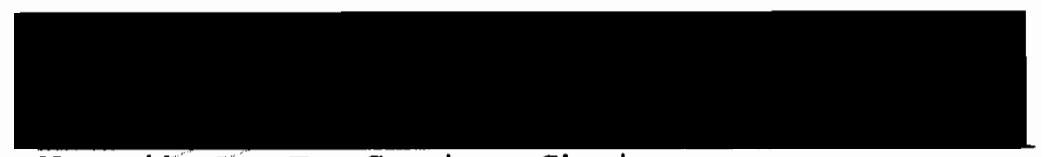

Naguib A. F. Greis, Chairman
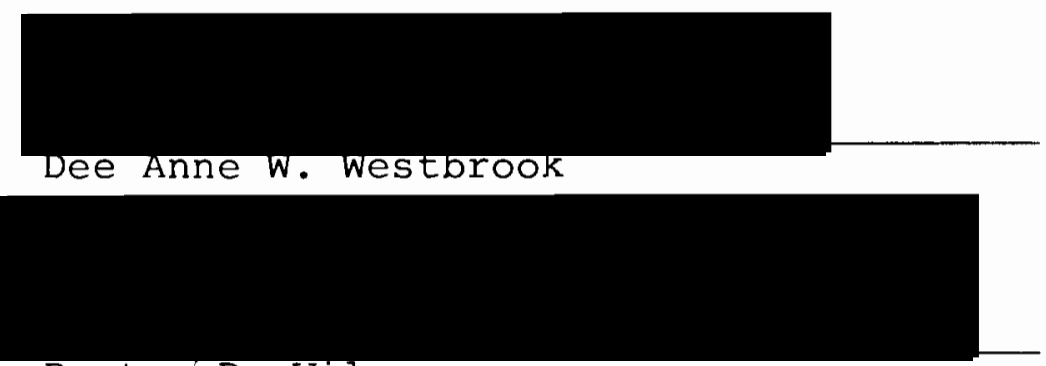

Baxter D. Wilson

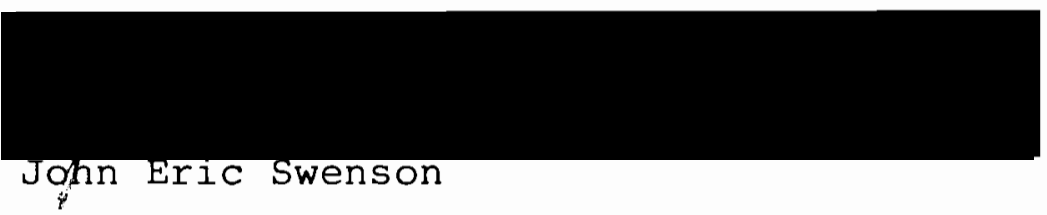

Intensive college-level ESL programs typically focus on building students' academic skills in English. Yet many ESL students leave the intensive programs only to find that they cannot sufficiently comprehend conversations with native English-speaking classmates or understand freshman-level lectures. While the students fre- 
quently perceive the problem as relating to the rapid speech tempo used by native speakers, an integral part of the comprehension problem is the pervasive use of modified forms of English, commonly called reductions, contractions, and assimilations.

The present research investigates whether comprehension of certain modified forms of spoken informal English can be used to measure students' level of proficiency. The research, based on an integrative approach to learning, hypothesizes that successful identification of informal forms may be as reliable and valid as standardized tests currently used to measure students' proficiency in grammar and listening comprehension. The instrument for conducting the research is a contextualized taped dialogue presented as a cloze exercise which depends on redundancy features of English in addition to knowledge of grammatical structures to help the subject reconstruct missing grammatical elements of the dialogue. Research data were not statistically significant to support the original hypothesis because of small sample size, but some general conclusions can be drawn. Conclusions and recommendations are discussed with attention to current trends toward content-based classes. 
A CONTEXTUALIZED GRAMMAR PROFICIENCY TEST

USING INFORMAL SPOKEN ENGLISH

by

SALLY WELLENBROCK HINRICH

A thesis submitted in partial fulfillment of the requirements for the degree of

MASTER OF ARTS

in

ENGLISH : TESOL

Portland State University

1988 
TO THE OFFICE OF GRADUATE STUDIES:

The members of the Committee approve the thesis of Sally Wellenbrock Hinrich presented June 2, 1988.

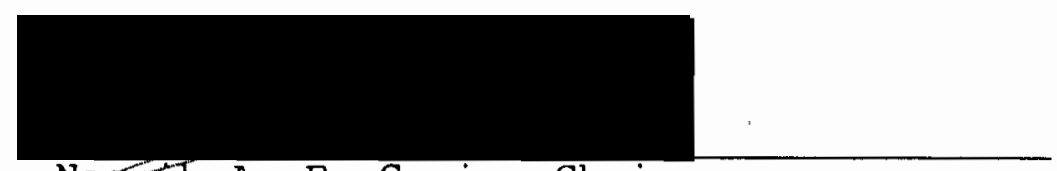

Nagurb A. F. Greis, Chairman

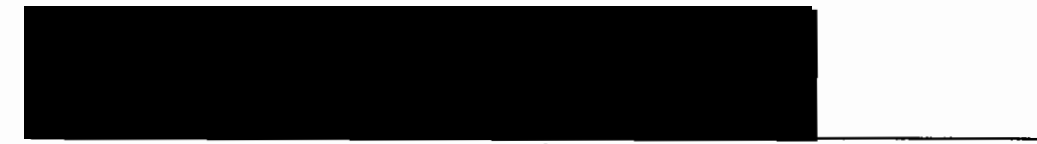

Dee Anne $\mathbf{W}$. Westbrook

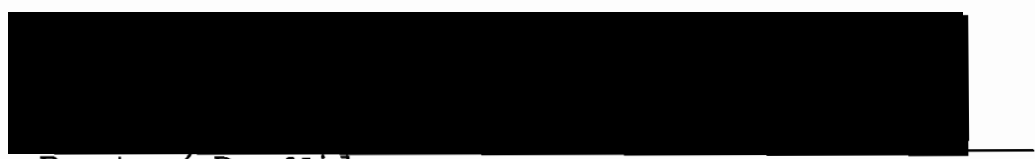

Baxter D. Wilson

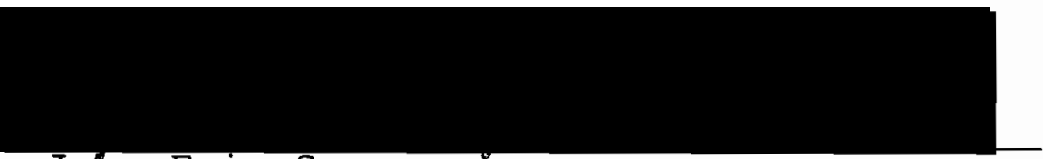

John Eric Swenson

APPROVED :

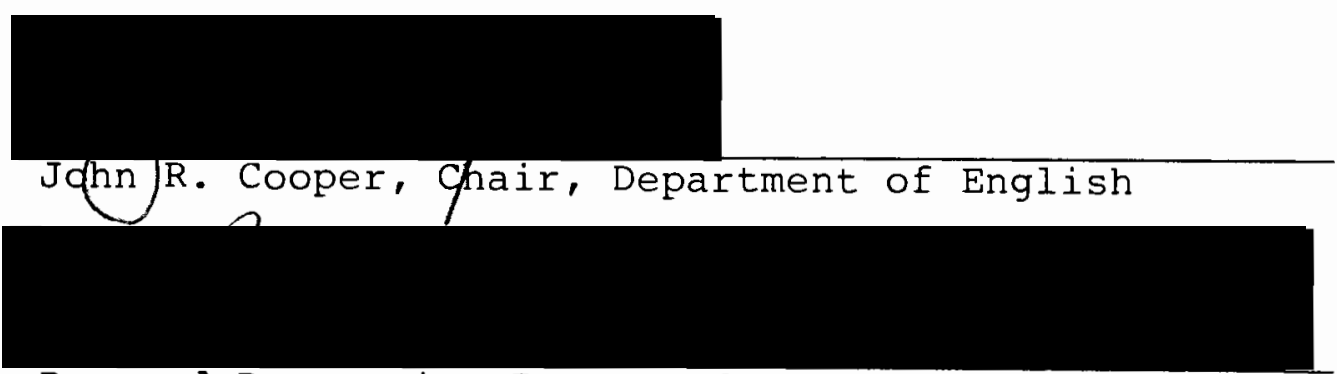

Bernard Ross, Vice Provost for Graduate Studies 
TABLE OF CONTENTS

PAGE

LIST OF TABLES ......................... iv

CHAPTER

I INTRODUCTION $\ldots \ldots \ldots \ldots \ldots \ldots \ldots \ldots \ldots \ldots \ldots$

II THEORETICAL FOUNDATIONS: A REVIEW OF

THE LITERATURE .................... 9

Modifications of Spoken English ....... 9

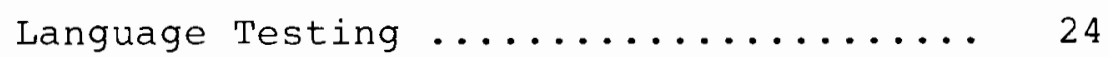

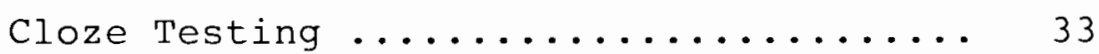

I I I CONTEXTUALIZED GRAMMAR TEST RESEARCH ..... 38

IV ANALYSIS OF RESEARCH DATA ............ 47

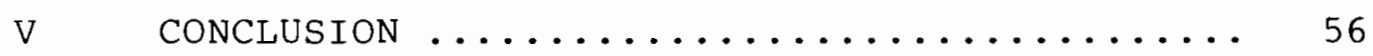

Conclusions ..................... 56

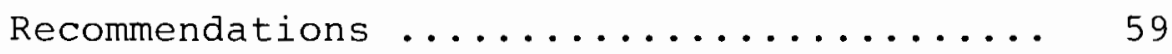

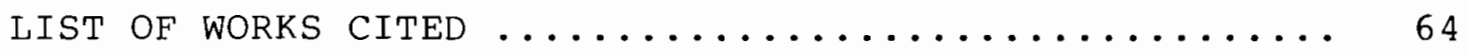

APPENDIX A: CONTEXTUALIZED GRAMMAR TEST ........... 69

APPENDIX B: MORPHEME ACQUISITION TABLES ........... 75 


\section{LIST OF TABLES}

TABLE

PAGE

I CELT Scores of ELS-Concordia Subjects ....... 38

II Contextualized Grammar Exercise:

Morphemes and Number of Occurrences ....... 49

II Means and Standard Distributions of Subjects'

Scores on CGE, MTELP, and CELT .......... 50

IV Correlation Coefficients Between CGE, CELT,

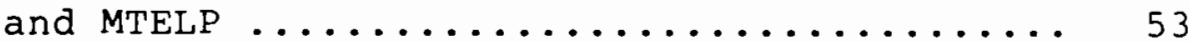

V Correlation Coefficients for CELT Subtests

of ELS-Concordia Subjects .............. 54 
CHAPTER I

\section{INTRODUCTION}

Current ESL teaching centers on language as communication rather than on language as a combination of distinct skills which can be combined to produce language. The focus on communicative acts through blending of grammar, pronunciation, vocabulary, and rhetoric skills is based on an integrative view of language. Supporting this national trend, several colleges in the Portland area are using or are moving towards using a "content-based" teaching approach. Instead of teaching the basic skills (listening, reading, writing, and conversation) separately, a portion of the ESL classes concentrates on a subject area, such as biology or American culture, and uses English as the medium of instruction. Specific exercises for the target skills such as vocabulary and grammar are developed from the context of the lesson.

Since many standardized tests use discrete elements of language to measure language skills, the focus on integrating skills in content classes presents a problem for measuring students' levels of learning. But if the student has become accustomed to an integrated approach, discrete-point tests may not allow the student to accu- 
rately demonstrate his mastery of the English language.

In doing research on topics of adult second language acquisition, research on pronunciation problems leads to readings on the role of $l$ istening comprehension in learning. Several studies cite Bowen's Integrative Grammar Test (1975) which employed modified forms of informal speech, as measured by the written production of the full grammatical form of specified informal forms to measure overall grammar proficiency. Henrichsen (1983) later modified Bowen's IGT pattern. Results supported Henrichsen's hypothesis that spoken informal forms affect the comprehensibility of input, and therefore the intake of English, for lower-level learners by reducing the clarity of the spoken language.

\section{RESEARCH HYPOTHESES}

At the present time, ESL pedagogy favors a communicative approach to teaching at all levels, including university programs. Therefore, a communicative, wholelanguage approach to testing seems desirable for testing the developing language proficiency of the student. Although Bowen's Integrative Grammar Test is based on a series of topically unrelated sentences, the IGT has been shown to correlate well with standardized tests. This correlation suggests that informal forms have a positively measurable relationship with the general knowledge of for- 
mal grammar.

The present research is based on the hypothesis that a test using spoken informal forms in a context (a dialogue between two speakers; transcript and answers are found in the Appendix) should prove as reliable and valid in ranking the student's level of competence in recognition and written production of English as a test using independent informal elements (the original Integrated Grammar Test). The types of items tested include sentences in both declarative and interrogatory format. The grammatical points targeted for study include the verb (to) $\underline{B E}$ used as both the copula and as progressive tense auxiliary, and pronouns used in the objective (accusative) and possessive cases.

The research also attempts to confirm the hypothesis that the contextualized test should positively correlate with rankings resulting from standardized test scores, although these scores may not be dependent on successful correlation with the Integrated Grammar Test. Scores for test groups are to be correlated and discussed as they relate to these hypotheses.

The remainder of this chapter will focus on characteristics of terms relevant to the present study and outline the information to be presented. 
DEFINITION OF TERMS

\section{Testing}

Tests to examine language $\mathrm{fit}$ into several broad categories, each depending on the specified need for information. In general, four types of tests are frequently used in language testing: proficiency, diagnostic, achievement, and aptitude. Proficiency tests evaluate global, or overall, competence, to indicate a student's general language ability. One example is the Test of English as a Foreign Language (TOEFL), commonly used to determine admission of foreign students into American colleges and universities. Tests in this category are usually administered in large numbers, and are generally machine scored. Within the general categories identified above, the instructor may choose on a continuum of objective to subjective techniques to discover the needed information (Brown 1987:224-226; Greis 1986:120).

The teacher must also decide on either a discretepoint or an integrative approach in developing the test items. Discrete-point tests are constructed to analyze any one of the four skills of language (reading, writing, speaking, and listening) by breaking those skills into subskills (i.e., phonology, morphology, syntax, etc.) and further dividing them into subcategories of each of those skills. The strength of discrete-point tests is that they 
can be constructed with high validity because the individual items can be consistently measured against sample groups. The principal argument against discrete-point testing is focused on the claim that language should not be broken into such finite components. Rather, language skills are so interdependent that they cannot be divided and then tested in isolation to truly represent the communicative capability of the learner.

Integrative tests are designed to require fairly rapid processing of sequences of language elements, which involves simultaneous use of several of the basic skills in combination with the knowledge of grammar (oller 1980:486). Opponents to integrative-style tests claim that the tests cannot be constructed with a high degree of validity. In the next chapter, several issues relating to integrative versus discrete-point testing will be discussed further. Specific topics will include views on both types of testing, the "general language proficiency factor," schema theory, and the redundancy factor.

Two common forms of integrative tests are the cloze and dictation tests. Cloze tests typically contain a text chosen from material used at the student's level and which has had words deleted systematically leither randomly or on a specified basis--every nth word). The student must fill in the missing word in each blank within the time period (5-10 seconds) allowed for each 
item during the test.

Informal or Modified English

Speech between native speakers is typically reduced in clarity to a minimum level required for comprehension and communication. As a result, the language appears out of focus to not just the beginning non-native learner, but to more advanced learners as well. Until the student can clarify various language segments, these modified forms remain elusive.

The various linguistic alterations of morpheme and word boundaries are incorporated under the general term "sandhi," as used by Crystal (1980). He points out that these "variations" include phonological changes which develop when "grammatical forms have been juxtaposed" (1980:311). The term sandhi comes from Sanskrit and refers to rules of potential grammatical combination in writing. However, sandhi is generally used in English linguistics to explain certain phonological changes caused specifically in pronunciation of the language. Specifically, sandhi-effects are the natural modification of certain phonemes or morphemes as consequences of informal pronunciation by native or fluent speakers of English. According to Morley (1980) these modifying effects include reduction, elision, and assimilation, where 
Reduction is weakened stress on particular words or morphemes within a phrase or sentence; elision is the dropping out of a sound resulting in shortened speech forms, and assimilation is the process by which sounds change phonetically to become more like neighboring sounds $(1980: 37-53)$.

Bowen (1975) points out that various combinations of sounds in phrases or sentences cause the sandhi effects. His Integrative Grammar Test is based on the hypothesis that the comprehension of informal English can be used as a means to measure overall grammar proficiency of high school and college students studying English. The present research aims to apply Bowen's research to a contextualized dialogue spoken at natural speed by native speakers of English. This exercise is then used to measure the overall grammar proficiency of three groups of college students in ESL programs.

ORGANIZATION OF THE STUDY

Chapter I has introduced the problem of measuring language proficiency based on communicative principles, specifically whether informal spoken English can be used to identify levels of language proficiency. Chapter II discusses the literature on informal spoken English as well as literature on several issues related to integrative and discrete-point testing.

Under the discussion of informal forms, listening comprehension and morpheme acquisition studies are also 
examined. The review of literature on testing includes a discussion of schema theory and the redundancy factor as well as investigating opinion and research on issues relating to the general language proficiency hypothesis and cloze-format testing.

Chapter III describes the research which gathered the data followed by a discussion of the techniques used to analyze the data. Chapter IV presents an analysis of the data and describes the relevance of the data to the working hypothesis. Chapter $V$ states conclusions of the study, and discusses potential applications and implications of the research for current ESL pedagogy and further study 
THEORETICAL FOUNDATIONS:

A REVIEW OF THE LITERATURE

Chapter I introduced the problems related to modifications of English phonology caused by the natural speech of native speakers. In addition, the contextualization of subject matter for classroom teaching was briefly discussed. In this Chapter, both topics will be developed in more detail. In the first section, a discussion of informal English forms focuses first on the relative ability of the non-native speaker to perceive and identify sounds in native speech, and then describes morpheme acquisition studies as they pertain to the informal forms used in the research test. The second section presents several topics related to testing language proficiency.

\section{MODIFICATIONS IN SPOKEN ENGLISH}

Brooks (1964) describes language as a "phenomenon of sound, not to be equated with communication, (for) communication can take place perfectly well without language" (1964:xi). The initial task for learning a language is to be able to discriminate sounds, and recognize how various sounds combine into meaningful words and then into expressive combinations of words and sentences. 
First language learners generally accomplish this task by the time they have entered grade school. They have systematically analyzed the stream of speech, found the characteristic basic units of sound, and begun to perfect the development of sounds into the speech heard in their environment. In spite of the complexity of this task, there is normally a minimum of explicit instruction involved by either parents or society as a whole. By the time the child has reached 10 years of age, the native language is internalized to a great extent, along with the grammatical rules of usage and the sociolinguistic rules of conversation (Moskowitz 1982:164-165).

This two-part process of discovering the rules of grammar (including phonology, syntax, semantics, lexicon and pragmatics) and analyzing speech for elements of sound is performed in a similar way. As the child breaks down each of these sub-systems into fundamental units, he or she then sets about to learn how to recombine the units into meaningful segments of language. The child is a practical linguist, working from overgeneralization of rules (from the most consistent patterns to the least consistent) and then gradually refining these rules to approximate the accepted form of language in the environment. 
This is particularly true in the actual pronunciation by the child, since the child must also deal with the physiological development of speech muscles, as well as with the cognitive development of language rules. In general, it can be said that the child comprehends much more than can be expressed. However, the basic comprehension of phonetics is already in place and psycholinguistic sound discrimination is quite well developed (Moskowitz 1982:166-67, 177-78).

For the adult second language learner, the process of identifying sounds and developing the discrimination skills is not so straightforward. After having developed the first language, the second-language learner soon recognizes that a relatively new phonetic system must be generated. But the learner finds that it is more practical and more productive to develop syntactic and semantic skills at the expense of the discrimination skill, often because of the constraints of time on learning. The second or foreign language learner must also overcome ingrained habits from the first language which serve to disrupt the learning process, frequently called "interference." Brown (1987) describes the complex interaction between the first and the target language as being "surely the most immediately noticeable source of error among second language learners." He goes on to describe its effects: 
The saliency of interference has been so strong that some have suggested that second language learning is exclusively involved with the overcoming of the effects of the native language. It is clear from learning theory that a person will use whatever previous experience he or she has had with language in order to facilitate the second language learning process. The native language is an obvious set of prior experiences (Brown 1987:82).

This is not meant to suggest that all previous language experiences act as interference. But for listening comprehension, at least some of the effects of the first language phonology do carry over negatively in many cases acting as a hurdle to full understanding of native speakers in the second language. Especially in conversational situations, even the more advanced student is often heard to say, "But they speak too fast for me to understand them!"

For students involved in learning a new language, it is necessary to consider the conditions which favor most efficient learning. Dulay, Burt, and Krashen (1982) identified four "macro-environmental factors" which affect the rate and quality of second language acquisition:

1. Naturalness of the language heard, including the effects of both natural and formal language environments,

2. The learner's role in communication, as both a passive and/or active participant, and the relative 
value of the "silent period" in learning a second language.

3. Availability of concrete referents, "the extralinguistic factors which can aid the learner in grasping the meaning of the strange sounds of the new language." These factors include the physical objects present in the classroom ("here and now") used in learning situations as opposed to objects or ideas which are out of the room or out of the present time frame.

4. Target language models, those persons who the learner feels represent the best language for the learner's specific purposes, i.e. peers over teachers, peers over parents, and own ethnic group members over nonmembers $(1982: 14-32)$.

In addition, Dulay, Burt, and Krashen focus on three "micro-environmental factors" which also affect the rate and quality of second language acquisition:

1. Frequency, the number of times a given structure is seen or heard by the learner. Yet frequency is not always the key to early acquisition, since certain "English grammatical items contribute little or nothing to meaning, (yet) occur more frequently than specific major content words which are acquired early in language development."

2. Feedback, response to either speech or writing by another person. This may be either (1) correction of 
the speech or writing by the teacher; or (2) expansion, where another person provides "systematic modeling of either the correct or more complete version of the (child's) utterances," a subtle form of correction without specifically pointing out the error (no second language studies were cited).

3. Salience, the perceived clarity of a sound structure (phoneme, morpheme, or word). The phonetic value, stress, and/or position of these structures found in the sentence are all subject to modification in English. The authors commented that morpheme acquisition studies do not satisfactorily explain why salience is not always the criterion for acquisition (Dulay, Burt, and Krashen 1982:32-40)

Naturally-spoken English is full of modified forms that provide models, yet students in homogenous-language classes seem to hesitate to adopt informal speech. Typically the class exerts strong peer influence on individual members and resists incorporating informal pronunciation during class sessions. The possible effects of peer pressure to limit use of English will be explored in the discussion of the research results.

Few of the modifications occur in graphic form in academic materials except for a limited number of contractions (those using not $=n^{\prime} t$, and possessives). The lack of graphic referents for informal English may be a 
major stumbling block for acquiring comprehension of reductions and contractions. In addition, many international students come to American ESL programs after studying English with a teacher who is also not a native speaker of English. As a result, ESL students have limited exposure to modified forms as used in native English speech. The opportunity for informal feedback is also limited if the student doesn't perceive the modification in the initial reception. Weakened stress, rapid speech, and lack of consistency with recognized grammatical patterns can cause not only the lack of comprehension for the student, but also they increase the chances for misunderstanding.

Morpheme acquisition in language learning

As learners have continued to make errors in spite of the best efforts of the teacher, studies have been conducted to find out why certain types of errors consistently occurred, but others seemed to readily solve themselves with minimum instruction required. Several studies were conducted during the 1970's to determine if there was a discernible pattern in acquisition of English as either a first or second language. Built on the framework of first-language studies by Brown and de Villiers \& de Villiers (1973), second language acquisition studies have indicated a general pattern of acquisition of cer- 
tain structures. While there are variations in the order of morpheme acquisition, since some structures show more variable acquisition order than others, a generally recognized body of information is available. Two tables of Morpheme Acquisition Orders are included in the Appendix.

In describing the natural sequence of first language learning for children, Moskowitz (1978) suggests that each child is innately practical in learning his or her native language linguistic patterns. First language studies discussed earlier in this Chapter indicate that a child will learn first those forms of language which are least variable. For example, the -ing ending (for the progressive tenses) is typically used before the -ed ending. The internal logic of the child finds that the -ing ending has no variant forms phonologically and therefore can be reliably used with confidence. Similarly, when learning a second or foreign language, fixed forms or inflections are confidently used before the irregular forms. Phonologically simple phonemic units such as prepositions (such as on and in) typically appear before the more complex behind (Moskowitz 1978:172).

Some of these structures that appear in acquisition studies are directly affected by the informal speech patterns common in the English language. But does knowing the approximate sequence of acquisition help the ESL 
teacher to prepare the student for informal speech with its many modifications? If comprehension of these forms should prove to appear at some definite level of learning, the teacher could time presenting the appropriate structures with observable progress in language proficiency. As yet, however, there are no modified form acquisition studies to aid the teacher. Research by Howard (1987) has shown that the amount of class time focused on modified, or "blended," speech varies considerably from teacher to teacher, and is also related to the perceived needs of the students enrolled in ESL programs.

\section{Studies of Modified Speech}

Bowen (1975) points out that the combination of various sounds in certain of phrases or sentences cause the modifying changes included in the definition of sandhi. When two or more words are spoken in an utterance, there are three possibilities which may induce the sandhi-effect: contraction, when two words are contracted to sound as one ("gonna"); reduction, the weakened stress of a phonemic sound or cluster (not $=/ \mathrm{nt} /$, "isn't"); and assimilation, a change and/or elimination of certain consonant sounds $(/ \mathrm{nt} /=/ \mathrm{n} /$, winter $=$ "winner"). Odlin (1978) tested a small group on the frequency and accuracy in oral use of certain contractions. Based on proficiency correlations with CELT scores, students were perceived as developing 
"separate rules" for forming contractions: one rule for

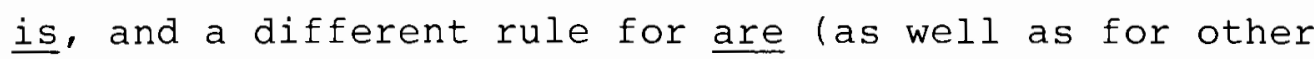
auxiliaries which appeared later in language development). Since the application of contraction rules varies with certain auxiliary verb forms, Odlin suggests that "the ability to perceive and use such forms is linked in crucial ways to aural comprehension skills and general ESL proficiency (1978:451-458).

Hill and Beebe (1980) further distinguish between the written and spoken forms: contraction is used to refer to a "written sequence of two words in which a word boundary has been obscured," and blending happens only in a "spoken sequence of two words in which a word boundary has been obscured." The difficulties for the non-native learner becomes two-fold:

(1) they tend to overuse contractions, and often hear two words as one; and (2) they underuse blendings, or fail to develop a receptive competence for the blending of words, thereby limiting their capacity to understand everyday speech (1980:300).

Informal forms tend to fluctuate phonologically in various speech environments. As Hill and Beebe point out, "not only do more blendings occur as the speech tempo increases, ...but speech tempo exerts subtle controls on the nature as well as the number of blending patterns in everyday speech" (1980:315).

In a classic study of English grammar, Jespersen (1933) appraised the number of modifications available to 
speakers of English. He noted "we have further alternations between two (or even three) forms of the same word, according as it is pronounced with or (more frequently) without sentence stress." He listed pronouns (me, we, he, and she) which use either "a long or short / $i /, "$ and cited three variations for your:

$$
\text { [juə(r)] [jo.(r)] [jə(r)], }
$$

as well as four variations for have. In addition to the phonemic alternations, he describes the change for not [not], which

becomes [nt] when fused with auxiliary verbs; and the $[n]$ is syllabic after a consonant (as in haven't), but not after a vowel (as in aren't) $(1933: 47-49)$.

In a later work, Jespersen (1946) examined stress patterns of English. He described four stress patterns used in English which he identified in relationship to the number of semantically important items in the utterance. In spite of these patterns, he noted that the words which were "naturally weak in most connections were pronouns and auxiliaries" (1946:151-159).

The element of rhythm and stress is important when discussing spoken English. English is expressed in clauses of various lengths, each with its relative importance to the total meaning of the entire communication. Because syllabic environment is a crucial factor in determining the actual pronunciation of each morpheme, those 
words with less crucial function to the overall message become either siurred or dropped in favor of the words or syllables which carry more significant content. Thus, rhythm and stress modify the phonemic composition of certain syllables in English, which can cause those phonemes to become indistinct and potentially incomprehensible to non-native speakers (Richards 1983:224).

The problem for the ESL learner and the ESL teacher is that informal forms exist "when Americans of almost all backgrounds and educational levels speak quickly or in an informal, casual manner" (Weinstein 1982). Yet, as Brown and Hilferty (1986), and Howard (1987) point out, teaching centered on the modified forms of spoken English is somewhat lacking, in spite of the fact that it is an accepted form of speech heard in many communicative acts.

Referring to the earlier discussion of the macroenvironmental factors listed by Dulay, Burt, and Krashen (1982), two factors are met for the second language learner attempting to deal with the problems of informal speech: naturalness of the language heard (since informal speech is widely available through radio, television, and public conversations); and the ability of the learner to passively receive these forms without the necessity to respond. However, the other two factors are not so easily found in the learning environment: slowing down the rate of speech does not necessarily recreate the missing pho- 
neme ("can't" does not become "can not" without changing pronunciation of the form "can't"); and even though the classroom may include use of informal forms, peer pressure can outweigh the model set by the instructor, especially pressure from the learner's ethnic group in a homogenous class.

In addition, these two micro-environmental factors seem to weigh heavily against acquisition of informal forms. While these forms are heard frequently in native conversations, the meaning of these morphemes may not be clear and has little content-specific information to further comprehension and saliency, since by definition reduction, contraction, and assimilation occur with minimal stress--the weakest points--in the rhythm of the utterance. How can we as teachers compensate for the preference for the student's native-group models while simultaneously encouraging the student's use of informal forms as a recognizable linguistic pattern?

\section{Routines and patterns}

One answer may be an appeal to the ability to learn "routines and patterns," as suggested in Krashen and Terrell (1983), and Dulay, Burt, and Krashen (1982). While the child or adult is busy learning grammatical rules, another type of learning seems to be taking place. There are a number of short phrases which are beyond the 
grammatical capability of the learner, but are used in regular speech. These phrases or short sentences are identified as "routines and patterns" and are often developed through imitation of native speakers. (Social greetings are an excellent example.) There may be an additional advantage in using these phrases for the second language learner. Krashen and Terrell mention that "routines and patterns" in the early stages of learning can be useful, when used in interactive situations. The ability to use more complex structures invites the listener to respond, providing additional language experience. $(1983: 43)$.

The attempt to go beyond grammatical certainty may parallel the use of "why?" by young children in learning their first language to stimulate further linguistic interaction, rather than to add to additional real information (Moskowitz 1978). It is an important step in second language learning when the learner attempts to exert conscious effort on the linguistic environment to add to language experience. The psychological confidence required to attempt the risk of interaction with other speakers may be one key to developing readiness for learning informal forms. Conrad (1985) noted that learners initially seem to direct much of their learning efforts toward syntactic and graphophonic information. However, as proficiency increases, there is evidence of 
greater attention directed to semantic cues and a correspondingly decreased attention to syntactic cues. These semantic cues may be derived in part through experimentation with the routines and patterns commonly found in the target language.

The use of specified patterns as a linguistic processing tool may vary between perception and production, as well as between two languages. Nattinger (1980) suggests that if "language production consists of piecing together the ready-made units appropriate for a particular situation, (then) comprehension relies on knowing which of these patterns to predict" (1980:341-343). When the learner moves to a second language, the relative size and/or number of these patterns may change in relationship to the first language. Therefore, the use of certain patterns requires a fairly sophisticated predictive ability.

In summary, the modifications of English identified as reductions, assimilations, and contractions occur in a number of uniquely complex pronunciation environments which can remain unclear to even the more advanced level ESL student. The focus of this research is to determine if recognition of these spoken forms can be used as a means to measure language proficiency. 


\section{LANGUAGE TESTING}

In this section, three issues on language testing which pertain to overall language proficiency will be discussed: the "general language proficiency" hypothesis; integrative and discrete-point testing; and cloze-dictation tests. Relative to these topics, linguistic principles that apply to modified spoken English will be presented, particularly pronunciation, psycholinguistic prediction, and redundancy.

Bernard Spolsky (1978) suggests that language testing development falls into three identifiable periods. The first period, termed the "prescientific," prior to the late 1950's depended on the principles set forth by the social sciences or humanities. From the early 1950's to the late 1960's, a second era developed around the structuralism prevalent in language teaching at that time. Spolsky identifies it as the "psychometric-structuralist" period. Language theory was concerned with contrastive analysis, behavioral psychology, and structural linguistics. Testing was concerned with attempts to find basic units, or components, of language, manifested in the "discrete-point" approach.

In the current period (dating from the late 1960's), methods of testing are focusing on an "integrative-sociolinguistic" approach. As in the field of language teach- 
ing, the theories of testing have moved towards an exploration of communicative competence (Spolsky 1978).

\section{The General Language Proficiency Factor}

A proponent of the existence of the general proficiency factor, Bernard Spolsky defined language proficiency as the facility with which an individual can cope with the communicative needs of a given task, or in a given situation (Aitken 1977:62).

Vollmer and Sang (1983) state that the theory of language proficiency assumes the possibility of distinguishing various stages in knowing a language. It is the learner's capability to control various language skills that is being examined. They suggest that language proficiency is unmeasurable directly, and must rely instead on performance of certain specified criteria (1983:31-32).

Vollmer and Sang (1983) claim that the general language proficiency factor can be used to defend rival hypotheses of language competency. According to the authors, the individual discrete skills should be measured by a "divisible competence hypothesis," but overall achievement should be measured by the level of accomplishment from a point in the past to the present moment of testing. The universal, or general, proficiency is described as a "unitary competence hypothesis," which tends to predict the potential "general capacity in handling a foreign 
language...as an instrument of social interaction in relevant future situations." After examining empirical evidence for both hypotheses, the authors concluded that neither is decisively favored over the other, and that the statistical data could be interpreted to the advantage of either hypothesis $(1983: 30-68)$.

While there is some popular support for a general language proficiency factor, there is also opposition. Farhady (1982) claims that "language proficiency" suggests a poorly stated concept because it cannot be adequately defined; therefore the development and use of 'proficiency tests' would be of little value in determining a true picture of a student's language skills (1982:44). As will be shown in Chapters III and IV, there is some evidence gained through research to support the integrative theory and testing approach which can measurably demonstrate overall language proficiency.

\section{Integrative and Discrete-Point Testing}

The changing theories of language teaching and testing have continued to create divergent opinions. One of the major issues of current testing research is centered on the relative merits of the integrative test versus the discrete-point test.

Oller and Oller (1983) make a general comparison between the two approaches to both teaching and testing. 
They suggest that the distinction between the synthetic and analytic approaches of Wilkins' Notional-Functional methodology parallel the distinction between discretepoint and integrative teaching. The authors further sugguest that these dichotomies are similar to Krashen's contrast between learning and acquisition. While there may be some debate over the accuracy of the comparison, the substance of the debate is whether language can be better learned by systematically mastering multiple rules and vocabulary presented in individual lessons, or whether learning should be accomplished by teaching "holistic communicative events" so that the student can analyze these events into "usable elements" (1983:21-22). Throughout this review of relevant literature, there is evidence of a continuing movement towards using a synthesis of both styles.

Cziko (1983) states that integrative tests can be used successfully to maximize differences in a subject's proficiency level by (1) requiring meaningful language behavior within a limited time, which uses similar cognitive processes as real language behavior; and (2) discriminating between high and low level achievers, reducing the possibilities of successful guessing to alter the score $(1983: 301-302)$.

Farhady (1983b) compared correlation coefficients reported in the literature concerning several well-known 
studies on development of integrative and pragmatic tests which used "well-established discrete-point tests as the validation criteria." After several statistical analyses, he concluded that "there is virtually no difference between discrete-point and integrative tests in what they measure or their results." He also cautioned that differing cultural and educational backgrounds may affect the students' ability to deal with certain types of tests. In summarizing his findings, he remarks that a variety of subtests, using both styles of testing will probably give the best overall picture of the student's achievement in learning English.

Background knowledge, according to Goodman (1967), may be more important to comprehension than semantics. His argument centers on the psycholinguistic principle of efficient selection of the most productive cues. The learner, or "language user must not simply know what to pay attention to, but what not to pay attention to" (1967:136-140). This echoes the observations made by Moskowitz, described in the earlier discussion of patterns of language acquisition, about the practical approach children take to learning their native language.

\section{Schema theory}

The practical approach to learning is developed through integration of experience (background knowledge) 
and learning skills. Basic to the concept of schema theory is that all new information must be incorporated into the learner's existing body of knowledge. The principles of the integrative theory of learning and testing closely parallel the definition of schema theory proposed by Carrell (1983) concerning the effects of schemata (the matrix of background knowledge) on successful reading comprehension. Carrell divides schemata into two categories. Formal schemata refers to the background knowledge of organizational styles of information and expectations for given situations (1983:86). Formal schemata of modified speech comprehension would include syntax, register, intonation, rhythm, and the underlying formal grammar of informal contracted speech.

Content schemata, the second category, refers to the background knowledge of content area covered by the text. Looking again at possible applications to modified speech, problems in comprehension may derive from the possible options in semantic interpretation, conversation topics, relative status of the speakers, or other contextual factors which influence the speaker's appropriate use of modified pronunciation.

Schemata can be applied to increasing comprehension in language learning as well:

Comprehending words, sentences, and discourse, then, involves much more than just relying on one's linguistic competence. In fact, one's 
linguistic competence is just one part of one's total background knowledge (1983:81-83).

Various cultural factors may affect the linking of formal and content schemata as well. Carrell explains that comprehension difficulties can arise when culturespecific knowledge is presumed by the text or that "content schemata may be absent within as well as across cultures" (1983:89). In a related article, Carrell and Eisterhold (1983) suggest that failure to comprehend is not just the learner's weakness in vocabulary as much as it is a weakness in content schemata. The authors recommend that the ESL teacher develop every possible opportunity to enhance culture-specific schemata that is available outside (as well as inside) the ESL classroom $(1983: 562-569)$.

The hypotheses to be investigated in the current research problem are founded in part on this link between formal and content schemata. The contextualized dialogue is used with the expectation that it will more fully explore the students' overall comprehension of English.

\section{Redundancy Factor}

Bernard Spolsky (1980) stated that there are "two vital truths about language: language is redundant, and it is creative." Within the rules of grammar, language elements can be creatively recombined in innumerable ways, and still be comprehensible to either a listener or reader 
who has never encountered a particular sequence before. The redundancy factor "effects a reduction in uncertainty by eliminating certain probabilities." As Spolsky pointed out, this seems inefficient at first glance. However, the long-term advantage of redundancy is that individual elements (or portions of those elements) in a given message can be obscured or even eliminated and the message is still comprehensible to the receiver (1980:28-29).

While native speakers develop this skill intuitively as an integral part of learning their first language, second language learners are at a distinct disadvantage. Redundancy features vary in proportion of use from language to language which implies that the number of inherent overlapping clues offered in the first language may be quite different than those of the second language. Spolsky points out that there is a marked difference between native and non-native speakers who can successfully recover missing items when outside interference (such as noise) has been deliberately added (1980:31-32).

Spolsky (1980) argued that the assessment of a subject's language proficiency must be based on his functioning in a much more linguistically complex situation than is provided by the one-element test (testing more than one skill at a time). Spolsky concluded that "a model of speech comprehension must include the ability to make valid guesses about a certain percentage of omitted 
elements" (1980:31).

According to Rivers (1982), English may be up to fifty percent redundant. She suggests that redundancy is a feature incorporated in varying degrees in all languages "to reduce to manageable proportions the amount of information in any one sound sequence." Ironically, the classroom may not provide this feature of language. Rivers states that "messages, such as those often used in foreign-language classes, often unwittingly reduce the amount of redundancy supplied by a speaker in a normal situation" (1982:267).

Gass and Varonis (1984) created interference by using the accented English of four native Arabic and Japanese speakers to test listening comprehension of native English speakers. Even though the exercise was executed completely in English, the native Englishspeaking subjects found some sounds unintelligible. The researchers discovered that subjects typically "attempted to put sounds into some framework that would make sense, rather than write nonsense." Gass and Varonis concluded that this was a direct effect from both background knowledge and real-world experience, and that comprehensibility is composed of variable effects of pronunciation, grammar, and familiarity with the accent, as well as the possible effects of non-native fluency and other social factors $(1984: 68-85)$. 
To summarize, redundancy features in English help to reduce possible errors and misunderstandings, while also permitting communication in spite of interference. According to Aitken (1977), "the correspondence between the ESL student's conception of English redundancy and the actual rules of English redundancy becomes an index of the student's overall language proficiency in English" (1977:65). This suggests that much of what is spoken adds little to the real message being conveyed, and that the listener has several opportunities to attempt to decipher the message.

The ability to comprehend a text while making skilled guesses as to the missing items is measured by successful completion of the exercise. Redundancy is provided in the context of the various sentences as well as by the various pronunciation features used in the conversation.

\section{CLOZE TESTS}

A cloze test is a test of language ability, constructed by deleting every $\underline{n} t h$ word (where $\underline{n}$ is usually between 5 and 10) from a passage the instructor has chosen from material considered appropriate to the student's level. The first and last sentences of the passage are usually left complete, and the whole passage should retain meaning if taken out of context. Students are then asked 
to fill in the missing blanks (Bowen, Madsen, Hilferty, $1985: 376)$

Because English employs redundancy features as a significant component of sentence structure, a sentence or phrase which contains an incomplete pattern (such as a blank) can be easily reconstructed by a native speaker based on other clues in the sentence. The reconstruction pattern is also stimulated to some degree by the psychological notion of closure, which compels the brain to attempt to eliminate a missing or obscured quantity by adding a known quantity from previous experience.

Kenneth Aitken (1977) outlined a brief history of cloze testing, beginning with Taylor, who reported the results of this kind of testing during the 1950's. Others identified with cloze testing include Darnell (1968), Anderson (1971), Oller (1972), and Stubbs and Tucker (1974). The latter researchers, Aitken claimed, were able to show high correlation of cloze tests and standardized tests which could be interpreted as evidence for overall language proficiency. He also suggested that productive and receptive language skills should be considered as aspects of the same underlying competence--implied by Goodman and described in the discussion of background knowledge and schemata. Aitken concluded that "a good general competency test of reading would be a good overall language proficiency test" (1977:59-66). 
The cloze test can be given in several forms. According to Bowen, a cloze test commonly uses three variations of deletion patterns:

(1) arbitrary or random, deletion of every nth word;

(2) selected or specific, where certain vocabulary items are systematically deleted;

(3) function word, correlating with grammar tests. To use cloze tests as measures of proficiency, a minimum number of blanks (usually 50) is developed for a target non-native speaker group and scored in comparison to a group of native speakers (Bowen, Madsen, Hilferty $1985: 376)$.

Another variation, describe by Davies, is the cloze-edit test, where the subjects are given a complete passage with no blanks. Instead, the subjects are evaluated on how accurately they mark out any extraneous words which have been randomly added throughout. The irrelevant words become the interference rather than added sound distractors (Bowen 1978:1-3; 1985:376).

Bachman (1982) suggests that a modified cloze passage, using "rational deletions of specified items las opposed to random deletions)," is capable of measuring both syntactic and discourse level relationships in a text." While random deletion more accurately represents authentic interference, it may be somewhat less effective 
because it may destroy the "syntactic and semantic relationships in the text" $(1982: 61,66)$.

Hanania and Shikhani (1986) examined possible interrelationships between three types of tests, including one using the cloze format and concluded that "the cloze technique does not necessarily produce valid proficiency tests." The validity may be "related more to individual items of the test that to general variables, such as a rate of systematic deletion" (1986:108-109).

Farhady (1983a) states that both reliability and validity for cloze tests cannot be adequately assessed specifically because of the contextual material required for the test. The interdependence of all items within the test can cause potential error when a student misses a series of items due to misunderstanding a portion of the context (1983a:257).

However, in testing for overall proficiency, mistakes in comprehending the context would seem to indicate the non-native speaker's lack of understanding in an authentic communicative situation, and therefore, be a reliable measure of the student's competency. The validity of cloze tests can also be correlated to standardized tests which are designed to test overall grammatical proficiency (see Bowen 1976).

In reviewing current opinions on issues relating 
to the integrative/discrete-point controversy, it is important to note that a consensus seems to be building toward using both kinds of tests (separately as well as in combination) to better evaluate and measure the ESL abilities and achievements of ESL students. For the purposes of this study, however, the cloze test format better serves to focus on the hypothesis of contextualization as a reliable indicator of proficiency. The following chapter will discuss the empirical research and will provide a description of the measures employed in the research.

This chapter has focused on two main areas of ESL research. In the first section, types of modified spoken English were described and several factors affecting learning a second or foreign language were considered. The second section reviewed literature pertinent to several issues in language testing specifically related to this research: the general language proficiency factor, integrative testing theory, and the concept of schemata. Chapter III will introduce the research subject groups and describe the research design and procedures involved.

Chapter IV will present an analysis of the data gathered during the research phase, and Chapter $V$ will discuss implications of the data for ESL pedagogy. 


\section{CONTEXTUALIZED GRAMMAR TEST RESEARCH}

Description of subjects

The subjects $(n=42)$ in this research were drawn from two groups of college-level ESL programs in the Portland area. Group A was composed of 13 subjects who were full-time students at the English Language School, Concordia college. All of these subjects attended class for at least three hours a day in a semi-intensive English program. At the time the research was being conducted, the students were in various intermediate to advanced level conversation, reading, and writing classes. All students took the Comprehensive English Language Test for Speakers of English as a Second Language (CELT) in April 1988, with a combined mean score of 70 (618) of the total possible 125 points for the combined Listening and Structure subtests.

TABLE I

CELT SCORES OF ELS-CONCORDIA SUBJECTS

\begin{tabular}{cccc}
\hline CELT: & Listening & Structure & Combined \\
mean raw score & 28 & 42 & 70 \\
mean converted & & & \\
to 8 & 55 & 56 & 61 \\
\hline
\end{tabular}


Group B included 29 subjects who were full-time students at the Center for English as a Second Ianguage, Portland State University. Students in this group were enrolled in the intensive English program at least four hours per day. These subjects were divided into two proficiency levels, 13 in intermediate level classes, and 16 in advanced level classes. These students took the Michigan Test of English Language Proficiency in May 1988 , with a mean score of 64 .

A final group consisted of 14 native speakers enrolled in a lower-division course in Intercultural Communication, including one volunteer TESL graduate assistant.

More than half of the 42 subjects spoke Japanese as their native language $(26$, or $62 \%)$. The other native languages were (number of students who spoke them): Arabic (6), Indonesian (4), Chinese (2), Korean, French, Swiss German, and Persian ( 1 each). All of the native speakers of English were from the United States. Although not all members of each group took the test at the same time, the three groups took the same test using the same taped dialogue with each test administered by the researcher.

It should be noted that Group $A$ is composed of Japanese speakers (with one exception) and is heavily influenced by the predominance of Japanese students at 
Concordia's English Language School. Less than ten percent of the school enrollment comes from other language groups. As a result, the majority of the students typically use Japanese exclusively for communication outside of class, since they have little contact with students from other language groups or native English speakers on the main campus. This is significant for this study since most of the English in the students' environment comes from teachers, who typically do not provide concentrated modeling of informal, modified English in the classroom.

In contrast, Group $B$ is drawn from a mixture of language groups, and students frequently use English for extra-curricular communication. This foreigner-foreigner contact, while providing many more opportunities to use English, would not necessarily provide native-like use of modified informal forms during conversation. It cannot be assumed, then, that either group has had extensive practice using reductions, assimilations, or contractions outside the classroom.

All of the subjects had been enrolled for at least one academic quarter ( 10 weeks) at both schools. The length of time that students had been in residence in the United States has not been used as a characteristic of this project because of the difficulty in accurately assessing the time of residence: some had been in the United States for a number of years, but not enrolled in 
ESL programs on a regular basis, other students had studied at other American schools, and some students from each group were involved in various home-stay situations with native English speaking families.

\section{Testing Measure}

The Contextualized Grammar Test is an exercise (CGE) which was used to measure the subjects' grammar proficiency. It was adapted from the Integrative Grammar Test (referred to as IGT) developed by Bowen (1975a, 1976) and the SandhiVariation Exercise (SVE), a modification of Bowen's test developed by Henrichsen (1983).

Bowen's test consisted of fifty unrelated sentences used twice during the test: once in modified form, and once with the complete form. Each pair of sentences exhibited a specific form of sandhi-variation, such as

"Jess's gone over the accounts already."

"Where'm I gonna get five thousand dollars?"

"Gonna get here for the soccer match?"

"Give'em a few days and they'll be back."

Subjects were instructed to write down the full grammatical form of the "second word you hear." Based on test results of 81 subjects, Bowen reported the IGT to correlate well (.789) with the grammar subtest and the listening comprehension subtest (.758) of the Michigan Test of English Language Proficiency (MTELP), and achieved a high correlation (.817) with the MTELP itself (1976:13). 
Henrichsen's exercise used fifteen of the IGT sentences to represent a variety of sandhi effects and to include different types of words affected (pronouns, prepositions, modals, etc.). Two forms of the sentences were used, each containing the fifteen sentences with mixed presence and absence of sandhi variations (assimilations, contractions, and reductions). The following sentences are samples from the SVE:

"Where did you ever get an idea like that?" "I am going to see him in just two weeks."

"He has done his homework, but I have not."

Sentences appeared once on each form, either with the sandhi-presence condition or without the sandhipresence condition (1973:111). Throughout Henrichsen's test, subjects listened to unrelated sentences and then attempted to write down the complete sentence in full grammatical form during a pause following the sentence. Only the second word of each sentence actually was scored, since that was the word which had been modified in pronunciation. Each test relied on the principle of redundancy (see discussion in the previous chapter) to supply cues to the proficient student to recall knowledge of grammar, schemata, and conversational strategies to fill in the reduced, contracted, or assimilated element.

Bowen's research using the concept of modified forms to assess overall grammatical proficiency proved to have marked correlation with other means of testing. But the 
IGT did not address the current focus on communicative acts in context as described in the discussion of schemata and cloze testing. The natural context of speech is the role interchange of speaker and listener between persons, and the development of topics within the conversation. In addition to simple declarative sentences, conversations have questions which are followed by answers, and further discussion topics may be supplied by either party of the dialogue.

The present research consisted of a dialogue format using two native speakers. A transcript of the dialogue, plus the correct responses appears in the Appendix. Topics were chosen arbitrarily to represent subjects relevant to college students during registration for a new term. Sentences varied in length (mean length $=7$ words), but all were spoken at natural speed. In addition to affirmative declarative sentences, there were six questions and one imperative structure. Sentences containing the target features (listed in Table III, Chapter IV) were followed by a five-second pause. Even though the sentences were unrelated, if the subject was unable to fill in one or two blanks, it was still possible to complete the rest of the dialogue.

Subjects were specifically reminded not to use written contractions, and to write out the full grammatical form. Two examples were presented before the test began, 
and both were written on a blackboard with the complete, correct word. One reason for avoiding contracted forms was to prevent the subjects from merely writing down one or two letters to imitate the perceived sound in the dialogue. It would be possible for the subject to write whos and not to know whether the actual verb form is had been used with a subject pronoun, or if the possessive pronoun had been spoken.

In addition to identifying phonological material, subjects had to access knowledge of the corresponding complete grammatical structures. Scoring was done by the researcher, and only correct grammatical forms were counted. The modified words were already in the subjects' vocabularies, which made spelling a minor consideration. Omissions were counted as errors, as were multiple answers in one blank. From an original test using 29 items, scores used in testing the hypothesis of this research were based on 25 items due to errors by native speakers, and one item that was missed by all but two non-native speakers will be discussed below.

\section{Procedure}

The Contextualized Grammar Test (or CGE) was administered during May 1988 at both colleges. Subjects were informed that the test was a variation of dialogue exercises used in class, focusing on informal English that might be 
used in conversations with native speakers as well as helping to identify high-level students who might need extra work with informal English before taking regular academic classes.

At each administration of the testing exercise, a transcript of the dialogue was passed out to students, with the text folded inside to avoid prereading of the material. Subjects were instructed to write both name and native language on the outside of the paper. The researcher briefly described the exercise in the terms explained above and gave the general instructions. Two sample sentences were presented orally, and were written on the board, with the missing element left blank. The group of subjects were asked to spontaneously provide an oral reply for the missing elements:

He (is) going to school.

Those books are (hers), not mine.

The researcher explained that the entire exercise would take ten minutes, then visually checked to see if all of the students had opened their papers to the dialogue, and started the tape. At the end of the dialogue, all papers were collected immediately. (The students in the advanced level class at PSU requested that they be allowed to take the test again, with time to discuss several items. One item, which was later discarded during an item analysis, was repeated in four separate at- 
tempts to discover the missing element.)

Four students at Concordia took the test a second time due to simultaneous enrollment in classes at both levels. A second testing (not included in the reported scores) showed little evidence of practice effect from the first test taken the day before (two students scored higher the second time, but the other two students scored lower than the first time).

After all test had been administered and relevant standardized test scores gathered, mean scores, median scores and standard deviations were calculated by groups according to the ESL class levels. An analysis and discussion of the data gathered in the research is reported in the following chapter. 


\section{CHAPTER IV}

\section{RESEARCH DATA ANALYSIS}

\section{$\underline{\text { Discussion }}$}

Due to the small size of the Concordia sample $(n=13)$, results are not significant enough to make conclusive hypotheses about the reliability of the test. The results of the PSU scores $(n=29)$ are somewhat more meaningful due to a larger number of subjects. Practice effect is not significant in analyzing this type of test, nor is difference in administration of the test.

Individual morphemes scored on the exercise are listed in Table II, showing the subjects' success in identifying the modified form in the dialogue. The data suggests that the singular copula is easily identified in the contextualized modified form, which agrees with the general patterns of acquisition suggested by Dulay, Burt, and Krashen (1982), as well as Krashen (1981), reported in Krashen and Terrell (1983). The data also tends to suggest a high level of familiarity with the accusative pronoun us and the auxiliary are (as used in the progressive tense), both of which fall into the early acquisition levels (levels I and II) as suggested in Burt, Dulay, and Krashen. However, yours (possessive pronoun) shows a good 
level of recognition by the students, even though Krashen (1981) considers possessive pronouns to be rather late in the general order of acquisition (see Appendix B).

Only $14(338)$ of the students responded correctly to blanks requiring did, a later-acquired morpheme (level III) according to both patterns just cited in this discussion. Some of the difficulty with this item may be its initial position in a question. A number of the students replaced the past tense form with the present tense do, which indicates familiarity with word order for questions, even though the past tense was not marked.

One item was deleted from the final scoring because it was consistently missed by non-native speakers, and was also missed by 5 out of 14 native speakers:

"We used (his) stereo and tapes for dancing."

The graduate assistant who was part of the native speaker group missed the item, and later made the following comment concerning her error:

I didn't think of the sentence in relation to the previous context. Instead, I simply wrote what I thought I heard, which was closer to 'used to....' even though I realized it didn't make any sense with the rest of the sentence.

Most students seemed to follow the dialogue, even though they didn't always fill in an answer. One student, whose scores were not included in this study, filled in the first four blanks correctly, and then became confused. He raised his hand, and indicated he wanted help, and re- 
fused to continue with the exercise even though the researcher attempted to show him the point at which the dialogue had progressed. He then attempted to look at another student's work rather than continue on his own paper.

TABLE II

CONTEXTUALIZED GRAMMAR EXERCISE:

MORPHEMES AND NUMBER OF

OCCURRENCES

\begin{tabular}{lcc}
\hline CGE Morpheme & $\begin{array}{c}\text { Number of } \\
\text { Occurrences }\end{array}$ & $\begin{array}{c}\text { Combined Correct } \\
\text { Responses } \\
\text { (Percent) }\end{array}$ \\
am & 1 & 86 \\
is & 8 & 85 \\
have & 2 & 78 \\
are & 2 & 73 \\
will & 1 & 71 \\
yours & 1 & 71 \\
us & 1 & 69 \\
them & 2 & 57 \\
her & 1 & 52 \\
his & 2 & 50 \\
him & 1 & 33 \\
did & 2 & 33 \\
\hline
\end{tabular}

The original hypothesis for the research was that a contextualized cloze test would be as reliable in testing overall grammatical proficiency as a test using unrelated items (see p. 3). The data from this study spreads the students across a range of 18 ( 25 possible) points indicating that a contextualized format has some value in differentiating students. Due to the small sample, how- 
ever, the result cannot clearly confirm the hypothesis. But the native speaker scores (mean 24.5, range=3) show that a random sample of academic-level native speakers can recognize the missing forms and successfully recreate the full grammatical item from the modified form. The mean scores and standard deviations of all test groups are given below in Table III.

\section{TABLE III}

MEANS AND STANDARD DEVIATIONS OF SUBJECTS SCORES ON CGE, MICHIGAN TEST OF ENGLISH LANGUAGE PROFICIENCY, AND COMPREHENSIVE ENGLISH LANGUAGE TEST

\begin{tabular}{|c|c|c|c|c|c|c|}
\hline \multirow[t]{2}{*}{ Group } & \multicolumn{2}{|c|}{ CGE } & \multicolumn{2}{|c|}{ CCELT } & \multicolumn{2}{|c|}{ MTELP } \\
\hline & mean & sd & mean & & mean & sd \\
\hline Concordia ELS $(n=13)$ & 14.5 & 3.9 & 70.0 & 13.9 & $\ldots--$ & --- \\
\hline PSU Level $3 \quad(n=19)$ & 17.3 & 3.7 & $-\cdots$ & $\ldots-$ & 61.9 & 10.9 \\
\hline PSU Level $4 \quad(n=10)$ & 20.6 & 2.2 & $-\cdots$ & ---- & 70.0 & 11.4 \\
\hline PSU Combined $(n=29)$ & 18.5 & 3.6 & $-\cdots$ & 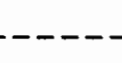 & 64.6 & 11.5 \\
\hline Total Subjects $(n=42)$ & 17.3 & 4.1 & --- & --- & & $-\cdots$ \\
\hline Japanese only $(n=26)$ & 16.5 & 4.2 & (ELS & and $\mathrm{I}$ & U comb & ned) \\
\hline Native Speakers (14) & 24.6 & 0.6 & ---- & ----- & --- & --- \\
\hline $\begin{aligned} \text { CGE: raw scores of tl } \\
\text { CCELT: CELT (combined } \\
\text { to percentage } \\
\text { MTELP: Michigan Place }\end{aligned}$ & $\begin{array}{l}\text { he Cor } \\
\text { d List } \\
\text { of to } \\
\text { ement }\end{array}$ & $\begin{array}{l}\text { extu } \\
\text { ing } \\
\text { al c }\end{array}$ & $\begin{array}{l}\text { ized } \\
\text { truct } \\
\text { rect }\end{array}$ & $\begin{array}{l}\text { Inswe } \\
\text { ted }\end{array}$ & $\begin{array}{l}\text { test } \\
\text { es c } \\
\text { perc }\end{array}$ & \\
\hline
\end{tabular}

The ELS-Concordia students' scores ranged from 7 to 21 with a mean of 14.5 and a standard deviation of 3.9 , with a range of 14 . These lower scores for the ELS stu- 
dents suggest that the less intensive program is providing a correspondingly smaller amount of English modified forms. It is also possible that listening skills for Group A are not as developed as their grammar (structure) skills although the individual CELT subtest scores show close correlation ( $L=55 \%$ correct and $S=56 \%$ correct) which suggests that the students' skills are similar to some extent. The effect of a rapidly spoken dialogue may be a more important factor in the lower scores, especially for those students who have limited contact with any type of English during hours in class or after school due to considerable peer pressure to avoid speaking English.

The PSU scores showed a significantly higher mean score $(18.5$ or 748$)$ but a similar standard deviation of 3.6. The scores ranged from 10 to 25 (408-1008), with a range of 15. The somewhat higher mean score (17.3) by the PSU level 3 students may be attributed to more contact with informal English, but it may also be due to sampling error. However, the slightly higher score of the level 4 is consistent with the expected increase of scores due to increased proficiency in both grammar and listening comprehension combined with the more frequent use of English as a medium of conversation. This can also be seen in the overall difference in mean scores for the Michigan test. One unexpected problem with the extended dialogue format was the number of pages required for the testing 
transcript used by the students. The presentation of the test for the first group had the dialogue printed on three separate pages. Students consistently (958) missed the first items at the top of the next two pages. When the test was given to the second group, it was slightly condensed to cover only two pages, and considerably fewer students made wrong responses. As a result, the items at the beginning of each new page were not scored in the final statistics.

The Contextualized Grammar Exercise correlates fairly well (.567) with the combined Listening and Structure CELT scores of the ELS subjects as shown in Table III. However, the correlation is somewhat less significant with the Structure test (.456), and has little significant correlation to the Listening subtest $(0.054)$. The higher correlation of the combined scores suggests that integrating the grammar and listening comprehension can better identify the overall grammatical and comprehension proficiency of the students. The correlation for the PSU students' MTELP is not as significant as the CGE-CELT figure, but is perhaps more accurate due to the larger sample size.

Bowen (1975, IGT discussed in Chapter III) reported that the Integrative Grammar Test showed a correlation of .619 with the MTELP with higher correlations achieved between the IGT and the Michigan Listening Comprehension (.758) and the Michigan Grammar subtest of the MTELP with 
the IGT $(.789)(1975: 13)$.

Bowen's data support the data from the present research which indicates that a test using informal modified English measures not only the achievement level of language structure (as shown by the greater CELT structure mean score over the CELT Listening mean score), but also suggests an integrative level of proficiency in English (expressed as the combined CELT mean score) which correlates at a higher level than the individual subtest scores. Comparisons of correlation coefficients are listed in Table IV for the CGE, CELT, and MTELP below.

\section{TABLE IV}

CORRELATION COEFFICIENTS BETWEEN CGE, COMPREHENSIVE ENGLISH LANGUAGE TEST

AND MICHIGAN TEST OF ENGLISH

LANGUAGE PROFICIENCY

\begin{tabular}{lcccc}
\hline \multicolumn{1}{l}{ Test Pair } & $\mathrm{R}$ & $\mathrm{T}$ & $\mathrm{df}$ & $\mathrm{p}$ \\
Group A & & & & \\
CGE-CCELT & .567 & 2.28 & 11 & $0.043^{\star}$ \\
CGE-LCELT & .054 & 1.93 & 11 & 7.884 \\
CGE-SCELT & .456 & 1.69 & 11 & 0.117 \\
Group B & & & & \\
CGE-MTELP & .432 & 2.49 & 27 & $0.021 *$ \\
\hline * & & & & \\
\hline
\end{tabular}

While the combined scores from the ELS students correlate well with the individual subtest socres, the intertest correlation between the LCELT and the SCELT is sig- 
nificantly lower as shown in Table $V$. The CELT manual suggests an intertest correlation of 0.69 between the Listening and structure test based on test results of 155 subjects. 1

TABLE V

CORRELATION COEFFEICIENCTS FOR CELT SUBTESTS

OF ELS-CONCORDIA SUBJECTS

\begin{tabular}{|c|c|c|c|c|c|}
\hline Test & Pair & $\mathrm{R}$ & $\mathrm{T}$ & $d f$ & $p$ \\
\hline $\begin{array}{l}\text { CCELT-I } \\
\text { CCELT-S } \\
\text { LCELT-S }\end{array}$ & $\begin{array}{l}\text { EELT } \\
\text { CELT } \\
\text { CELT }\end{array}$ & $\begin{array}{l}.764 \\
.947 \\
.585\end{array}$ & $\begin{array}{l}3.93 \\
9.86 \\
2.39\end{array}$ & $\begin{array}{l}11 \\
11 \\
11\end{array}$ & $\begin{array}{l}.002 \star \\
<10(-6) \star \\
.036^{\star}\end{array}$ \\
\hline $\begin{array}{l}\text { LCELT: } \\
\text { SCELT : } \\
\text { CCELT: }\end{array}$ & \multicolumn{4}{|c|}{$\begin{array}{l}\text { Listening subtest } \\
\text { Structure subtest }\end{array}$} & $\begin{array}{l}\text { Structure subtest } \\
\text { combined scores--Listening and structure }\end{array}$ \\
\hline
\end{tabular}

The cloze test format gave the students some clues to the context for the missing elements. Upon being examined for error patterns, the research showed errors caused by students filling in an appropriate part of speech to the word or words immediately preceding the blank space rather than the word which was actually spoken:

"I hope your luck is better than (ours)."

A typical student error was to insert mine, which is contextually appropriate but incorrect according to the

'Data from the Comprehensive English Language Test Technical Manual, preliminary edition. 1970. 
dialogue.

As a result, the research statistics may not account for subjects merely reading the sentence. This may be especially true for the lower-scoring students who are reading because they can't follow the dialogue.

The research results are somewhat inconclusive due to the small sample size. However, the results imply that there is potentially significant value in developing contextualized exercises to identify various levels of overall language proficiency, and to focus the student on the need to develop the ability to comprehend informal modified English along with the grammatical English taught in the classroom. 


\section{CHAPTER V}

\section{CONCLUSIONS}

This research has attempted to investigate whether certain features of informal spoken English, modified by native speech patterns, can be used successfully to measure the overall language proficiency level of students in college-level ESL programs. Using integrative testing, the research centered on the hypothesis that successful identification of informal forms may be as reliable and valid as standardized tests currently used to measure students' proficiency in grammar and listening comprehension. In spite of the small size of the testing sample, the research data show that the hypothesis may have validity with larger testing groups.

In reviewing the literature, patterns of morpheme acquisition in both first and second language learning were considered as they relate to informal English proficiency of ESL students. The effects of routines and patterns were noted since informal spoken English is often derived from established patterns that occur during social discourse. It would be helpful to know if there is an identifiable level of learning that is necessary before ESL learners can begin to efficiently acquire informal 
forms either as a preset pattern or as independent units to be used freely in speech. Further research may provide a general pattern of modified-form acquisition that can aid the instructor in successfully presenting these forms. In addition, textbooks based on such an acquisition pattern could be developed to help students move more effectively towards successful comprehension of native speakers.

ESI students who have the opportunities to frequently hear and use informal forms have not significantly scored native-like proficiency levels on the various integrative tests. This may be due in part to the transitory nature of modified forms: present primarily in spoken English, they are relatively uncommon in written English. Informal registers of English are presented in many ESL textybooks, but do not accurately represent reductions and assimilations as actually heard in normal speech patterns. 1 Part of the difficulty in presenting informal forms accurately may be the lack of standardized spelling of the various words and phrases lexcept for certain types of contractions).

Books such as Weinstein's Whaddaya Say? attempt to build familiarity with informal forms. However, the orthography of the informal forms is seldom seen in other

${ }^{1}$ See Stempleski, Rice, and Falsetti: Getting Together; Molinsky and Bliss: Expressways; Jones and von Baeyer: Functions of American English for examples of conversations using informal English. 
materials, and is further confusing to the students because it represents a style of spelling that is usually unfamiliar to them.

The interrelationship between knowledge of structure and knowledge of vocabulary, culture, and social context is also pertinent to the present research. Even though the ESL learner has mastered the formal rules of the language, the meaning and appropriate use of many common modified forms remains elusive. This seems especially relevant to problems of the Japanese subjects in Group $A$ who seem to have a noticeable degree of difficulty with oral English usage, but have relatively high success rates on written examinations concerned with structure and other language skills.

Although the research data showed limited correlation with standardized grammar and listening tests, there may be additional factors which influenced the test results. A valid oral test requires the speakers use native-like pacing of speech throughout the dialogue, whereas in actual conversation, the learner would have numerous opportunities to stop the speaker in order to identify blurred words or unfamiliar meanings. Frustration or anxiety levels cannot be measured by the tests represented in this study, possibly creating an affective variable that may prove significant in measuring the learner's ability to demonstrate language achievement. 
Culturally dictated learning styles may also determine the rate at which students begin comprehending and attempting to use modified English. The student's native language may have to be considered along with cultural learning styles if the student's native language does not use informal speech to the same degree or in the same situations as it is used in English. Culture-specific research may shed more light on this aspect of language learning.

Although researchers do not agree as to whether an integrative test can reliably measure more than specific listening comprehension and/or grammatical competency, the current popularity of schema theory suggests that an integrative approach to teaching language skills does benefit the learner. Therefore it seems plausible that an integrative approach to testing would correlate well with the learner's emerging ability to use the language.

\section{RECOMMENDATIONS}

The comprehension of informal English depends not only on familiarity with spoken patterns, but must be augmented with a solid grasp of grammatical structures and the appropriateness of various semantic options to be considered as a valid measure of overall proficiency. Comprehension of modified English may be more a product of careful instruction rather than the result of exposure to 
native speakers. Yet it has been demonstrated that many ESL students have not been exposed to the various features of informal English because the instruction in the native country was through non-native speakers of English. As the students build skill in understanding and using formal and academic English, activities involving general comprehension of the informal language should also be encouraged. For some students, visits to shopping malls or student activity centers can provide opportunities to record specific instances of informal use, and also provide authentic models to be analyzed and practiced in the classroom.

The content-based courses mentioned at the outset of this study are developed from the concept that learning is more efficient when presented in a realistic context which avoids an artificial focus imposed by some particular grammatical or vocabulary structure, requiring the learner to incorporate many of the features of language with which he or she may be familiar from the native language. Rhythmic pronunciation exercises, songs, and role plays can also be used in various contexts to aid the understanding of articulation and stress patterns which create the environment for modified speech patterns. The ESI instructor is ultimately responsible for creating opportunities for the students to experience informal English in settings not only in the classroom, but also suggesting 
potential sources outside the classroom. It is the experience with the success in conversation with native speakers which can create the most authentic learning environment.

\section{Suggestions for Further Research}

In addition to the pedagogical applications suggested by this study, further research is needed to investigate the order that auxiliary verbs and modals begin to appear in writing and conversations. The comprehension and use of informal forms in conversation may be directly related to knowledge of these verbs. Grammar proficiency as well as the use of routines and patterns may be involved in this type of study. Additional studies using an integrative approach would be useful to examine the possibility of a learning hierarchy of informal forms similar to the hierarchy of grammatical morphemes posited by Dulay and Burt, and others (see Dulay 1982). Using a large sample, research may be able to predict which informal forms appear first, and whether there is a pattern unique to specific language groups. With sufficient samples, it may be possible to determine whether there is a stage of grammatical or conversational learning which must be achieved before successful learning of informal forms can be readily accomplished by the majority of learners.

A more accurate contextualized proficiency test would 
have to have a sufficient number of items to expose the students to each specified informal form several times, yet not be so lengthy that the test becomes unwieldy for the instructor to administer in the classroom. It may be that the test would have to be divided into several parts, each concentrating on a particular type of informal usage. However, an ideal test would also have to attempt to present the language forms in a realistic situational context incorporating extraneous noises, conversational pauses and repeated words related to the basic dialogue.

The results of the research suggest that it is the ESL classroom which offers the best overall situation for the initial learning of informal forms. There, the student has time to focus on individual language features with the aid of a native speaker who can also suggest additional cues to help identify underlying structures and correct misperceptions of certain sounds. For students abroad where native speakers may not be available to provide suitable modeling of informal forms, the EFL teacher may be able to use tapes of native speech to supplement the lessons. In addition, books and written exercises could be employed to help bridge the gap between non-native and authentic native speech.

As modified forms of English are integrated into the mainstream ESL and EFL curricula, tests which measure comprehension through reduced and contracted English can 
be used in the classroom. Using these tests, the teacher can more readily identify weaknesses of those students who are not yet ready to move into mainstream academic classes as well as those students who cannot seem to develop listening comprehension skills sufficiently to function in a general conversation with native speakers. 


\section{LIST OF WORKS CITED}

Aitken, Kenneth. 1977. Using Cloze Procedure as an Overall Language Proficiency Test. TESOL Quarterly $11(1): 59-67$.

Alderson, J. Charles. 1983. The Cloze Procedure and Proficiency in English as a Foreign Language. In $\mathrm{J}$. Oller (Ed.), Issues in Language Testing Research (pp. 205-218). Rowley, MA: Newbury House.

Bachman, Lyle. 1982. Trait Structure of Cloze Test Scores. TESOL Quarterly 16(1):61-70.

Bailey, Nathalie, Carolyn Madden, and Stephen Krashen. 1974. Is There a "Natural Sequence" in Adult Second Language Learning? Language Learning 24:235-243.

Bloomfield, Leonard. 1933. Language. New York:Henry Holt.

Bowen, J. Donald. 1975a. An Experimental Integrative Test of English Grammar. Workpapers on TESL (UCLA) $9: 3-17$.

Bowen, J. Donald. 1975b. Patterns of English Pronunciation. Rowley, MA: Newbury House.

Bowen, J. Donald. 1976. Current Research on an Integrative Test of English Grammar. RELC Journal

$7(2): 30-37$.

Bowen, J. Donald. 1978. The Identification of Irrelevant Lexical Distraction: an Editing Task. TESL Reporter $12(1): 1-3,14-16$.

Bowen, J. Donald, Harold Madsen, and Ann Hilferty. 1985. TESOL Techniques and Procedures. Rowley, MA: Newbury House.

Brooks, Nelson. 1964. Language and Language Learning: Theory and Practice. New York:Harcourt, Brace \& Co.

Brown, James, and Ann Hilferty. 1986. Listening for Reduced Forms. TESOL Quarterly 20(4):759-763. 
Carrell, Patricia. 1983. Some Issues in Studying the Role of Schemata, or Background Knowledge in Second Language Comprehension. Paper presented at the $17 \mathrm{th}$ Annual TESOL Convention, Toronto, Canada, March, 1983.

Carrell, Patricia, and Joan Eisterhold. 1983. Schema Theory and ESL Reading Pedagogy. TESOL Quarterly $17(4): 553-573$.

Carroll, John B. 1983. Psychometric Theory and Language Testing. In J. Oller, Jr. (Ed.), Issues in Language Testing Research (pp. 80-107). Rowley, MA:Newbury House.

Chapelle, Carol, and Cheryl Roberts. 1986. Ambiguity Tolerance and Field-Independence. Language Learning $36(1): 27-45$.

Conrad, Linda. 1985. Semantic vs Syntactic Cues in Listening Comprehension. Studies in Second Language Acquisition $(7,1): 59-72$.

Croft, Kenneth. 1980. Language Testing Today: an Interview with John oller. In K. Croft (Ed.), Readings on English as a Second Language for Teachers and Teacher Trainees (pp. 481-491). Boston, MA:Little, Brown.

Crystal, David. 1980. First Dictionary of Linguistics and Phonetics. Boulder, Co:Westview Press.

Cziko, Gary. 1983. Psychometric and Edumetric Approaches to Language Testing. In J. Oller (Ed.), Issues in Language Testing Research (pp. 289-308). Rowley, $\overline{M A}$ : Newbury House.

Dulay, Heidi, Marina Burt, and Stephen Krashen. 1982. Language Two. New York:Oxford University Press.

Farhady, Hossein. 1982. Measures of Language Proficiency from the Learner's Point of View. TESOL Quarterly $16(1): 43-59$.

Farhady, Hossein. 1983a. New directions for ESL Proficiency Testing. In J. Oller (Ed.), Issues in Language Testing Research (pp. 253-270). Rowley, MA: Newbury House. 
Farhady, Hossein. 1983b. The Disjunctive Fallacy Between Discrete-Point and Integrative Tests. In J. Oller (Ed.), Issues in Language Testing Research (pp. 311-323). Rowley, MA: Newbury House.

Gass, Susan, and Evangeline Varonis. 1984. The Effect of Familiarity on the Comprehensibility of Nonnative Speech. Language Learning 34(1):65-89.

Goodman, Kenneth. 1967. Reading: a Psycholinguistic Guessing Game. Journal of the Reading Specialist $4: 126-135$.

Goodman, Kenneth. 1973. Psycholinguistic Universals in the Reading Process. In F. Smith, Psycholinguistics and Reading (pp. 135-142). New York:Holt, Rinehart \& Winston.

Greis, Naguib. 1986. TESOL Handbook for Prospective Teachers of English to Speakers of Other Languages. Portland, OR: Portland state University.

Hanania, Edith, and May Shikhani. 1986. Interrelationships Among Three Tests of Language Proficiency: Standardized ESL, Cloze, and Writing. TESOL Quarterly 20(1):97-109.

Harris, David, and Leslie Palmer. 1970. Comprehensive English Language Test for Speakers of English as a Second Language (CELT): Technical Manual. New York:McGraw-Hill.

Henrichsen, Iynn. 1983. Sandhi-Variation: a Filter of Input for Learners of ESL. Language Learning $34(3): 103-126$.

Hershenhorn, Suzanne. 1979. Teaching Iistening Comprehension Using Live Language. In M. Celce-Murcia and L. McIntosh (Eds.), Teaching English as a Second or Foreign Language (pp. 65-73). Rowley, MA: Newbury House.

Hill, Clifford, and Leslie Beebe. 1980. Contraction and Blending: the Use of Orthographic Clues in Teaching Pronunciation. TESOL Quarterly 14(3):299-323.

Howard, Grace. 1987. The Teaching of Speech Sound Blending in College-level ESL Programs. Unpublished MA:TESOL Research. Portland State University. 
Jespersen, Otto. 1933. Essentials of English Grammar. New York:Henry Holt \& Company.

Jespersen, Otto. 1946. A Modern English Grammar: On Historical Principles. Part I: Sounds and Spellings. London:Allen \& Unwin.

Klein-Bradley, Christine. 1983. A Cloze is a cloze is a Question. In J. Oller (Ed.), Issues in Language Testing Research (pp. 218-229). Rowley, MA: Newbury House.

Krashen, Stephen, and Tracy Terrell. 1983. The Natural Approach: Language Acquisition in the Classroom. Hayward, CA:Alemany Press.

Laesch, K.B., and Anne van Kluck. 1987. The Cloze Test as an Alternative Measure of Language Proficiency of Children Considered for Exit from Bilingual Education Programs. Language Learning 37(2):171-189.

Markham, Paul, and Michael Latham. 1987. Influence of Religion-specific Background Knowledge on the Iistening Comprehension of Adult Second Language Students. Language Learning 37(2):157-170.

Morley, Joan. 1980. Improving Spoken English. Ann Arbor, MI:University of Michigan Press.

Moskowitz, Breyne Arlene. 1978. The Acquisition of Language. Scientific American 239(5):92-109.

Nattinger, James. 1980. A Lexical Phrase Grammar for ESL. TESOL Quarterly 14(3):337-344.

Odlin, T.M. 1978. Variable Rules in the Acquisition of English Contractions. TESOL Quarterly 12:451-458.

Oller, John W. 1973. Cloze Tests of Second Language Proficiency and What They Measure. Language Learning 23(1):105-118.

Oller, John W., Jr. 1983. Issues in Language Testing Research. Rowley, MA: Newbury House.

Oller, John W., and John W. Oller, Jr. 1983. Integrated Pragmatic Curriculum: a Spanish Program. In J. W. oller, Jr. (Ed.), Methods That Work: a Smorgasbord of Ideas for Language Teachers. Rowley, MA: Newbury House. 
Oller, John W., Jr., and Patricia Richard-Amato, Eds. 1983. Methods That Work: a Smorgasbord of Ideas for Language Teachers. Rowley, MA:Newbury House.

Oller, John W. and Virginia Streiff. 1975. Dictation: a Test of Grammar-based Expectancies. In R. Jones and B. Spolsky (Eds.), Testing Language Proficiency (pp. 71-88). Arlington, VA:Center for Applied Linguistics.

Pei, Mario. 1966. Glossary of Linguistic Terminology. New York: Columbia University.

Radford, Andrew. 1981. Transformational Syntax. New York:Cambridge.

Richards, Jack C. 1983. Listening Comprehension: Approach, Design, Procedure. TESOL Quarterly $17(2): 219-239$.

Rivers, Wilga. 1980. Listening Comprehension. In K. Croft (Ed.), Readings on English as a Second Language for Teachers and Teacher Trainees (pp. 265277). Boston, MA:Little, Brown, and Company.

Schumann, John. 1975. Affective Factors and the Problem of Age in Second Language Acquisition. Language Learning 25(2):209-235.

Spolsky, Bernard. 1980. What Does It Mean to know a Language? In K. Croft (Ed.), Readings on English As a Second Language for Teachers and Teacher Trainees (pp. 26-41). Boston, MA:Little, Brown, and Company.

Temperly, Mary S. 1983. The Articulatory Target of Final -S Clusters. TESOL Quarterly 17(3):421-436.

Vollmer, Helmut, and Fritz Sang. 1983. Competing Hypotheses about Second Language Ability: a Plea for Caution. In J. Oller, Jr. (Ed.), Issues in Language Testing Research (pp. 29-79). Rowley, $\overline{M A}$ : Newbury House.

Weinstein, Nina. 1982. Whaddaya Say? Englewood Cliffs, NJ : Prentice-Hall. 


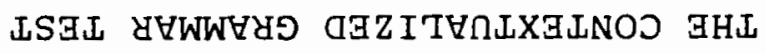

$\forall$ XIGNG $d d$ 


\section{ADMINISTRATION AND CORRECT RESPONSES}

Directions given orally at each administration by the researcher:

(1) Write your name and native language at the top of the paper.

(2) "You will hear two people talking to each other on the taped dialogue. They are friends, so they are using informal English.

You should follow the dialogue on your paper, and fill in the correct grammatical form of the missing word for each blank space. Here are two examples (researcher writes the following sentences on the board:

(a) $\mathrm{He}$ going to class (He's)

What's the correct form of the missing word? Students reply orally: He is.

Researcher fills in the blank on the blackboard.

(b) That book isn't ' I think it's mine. (hers) What's the correct form of the missing word? Students reply orally: hers.

Researcher fills in the blank on the blackboard. Each sentence with a blank is followed by a short pause, so you can fill in the blank. Don't stop to look back at the sentences you have already heard before. Just keep working along with the tape. Don't worry if you miss 
one blank, just move on to the next one.

(3) Any questions? Then turn over your papers and let's get started. 
Name

Native Language

$\mathrm{Hi}$, how are you? I was just at the business office paying my tuition for next term. What a mess! Have you been to register today?

No, I'm going there next. I haven't finished filling out the registration forms yet. (Did) you get all the classes you need?

I went early this morning to make sure. What classes (are) you planning to take?

I need a Physical education class, and an American History class. Oh, and I (have) got to get into the first year Algebra class this term. Do you know who (is) teaching it?

I think it _ (is) Professor Williams this time. My sister and I had Dr. Smith last year. I hope your luck is better than (ours). He gives so much homework, and there's a test every week. (His) tests are so long that nobody ever finishes them. Well, I have to take the classes anyway. Next term I (am) supposed to take Chemistry, and I have to pass Algebra before I can get in that class. And I want to take Dr. Wilson's English History class. I hear he (is) a good teacher. Hmmm, have you taken any of his classes? 
Not yet, but I've signed up for (his) Modern Poetry course. Anna says she learned a lot about poetry and writing in the class. And his final exam wasn't very hard. Dr. Wilson just asked (them) to write a short poem about the class.

Do you know if she (will) sell me her English History books? I was in the book store, and the price of those textbooks, well, it (is) too much money for one class.

I could ask her tonight. We (are) going out for pizza and a movie. She might still have them, since the class wasn't offered last term. But she usually sells (them), to pay for the ones she buys for the next term. I (will) let you know tomorrow.

Thanks. Say, (did) you hear if Nancy is back for this term? She had to go home last month for family business, and I haven't heard from her.

I think her father (is) starting a new business, and she's probably helping him get organized. She (is) the only child, and her mother is too busy with (her) own job to help work at the new office. I'm going by Nancy's room this afternoon, and I'll check to see if her roommate has heard from (her) yet.

I hope she (is) back. I enjoyed studying with her during finals week. Hey, there (is) Mike -- my 
brother's friend. Do you remember (him) from the party we had last week? We used (his) stereo and tapes for dancing. That reminds me, I have still got those French tapes of (yours). I haven't finished copying them yet, but I'll get (them) back to you before the weekend. No problem, I won't have time to listen to them anyway. Do you know what time it is? I (have) got to go to the post office before I go back to my room. It's about 12:30. Let (us) get some lunch before we go back to the business office. o.K.... and I've got to finish registering, too!!

(END OF DIALOGUE) 
APPENDIX B

MORPHEME ACQUISITION ORDER TABLES 
GRAMMATICAL MORPHEME ACQUISITION HIERARCHY

\section{Group I}

Case (nominative/accusative)

Word order (in simple declarative sentences)

\section{Group II}

Singular copula ('s/is: He's fat.)

Singular auxiliary ('s/is: She's dancing.)

Plural auxiliary (are: They are sleeping.)

\section{Group III}

Conditional auxiliary (would: I would go if...)

Long plural (-es: I see the houses.)

\section{Group IV}

Perfect auxiliary (have: She would have seen him if...) Past participle (-en: He would have eaten it if...)

Source: Dulay, Burt, and Krashen (1972:34). 
AVERAGE ORDER OF ACQUISITION OF GRAMMATICAL MORPHEMES (For Adults and Children)

\author{
Group I \\ Morpheme - ING (progressive tense) \\ Plurals \\ Copula (TO BE) \\ Group II \\ Auxiliary (progressive) \\ Articles ( $A, T H E$ ) \\ Group III \\ Irregular Past \\ Group IV \\ Regular Past \\ 3rd Person Singluar (-S) \\ Possessive $(-S)$
}

Source: Krashen and Terrell (1983:29). 